\title{
(2) OPEN ACCESS \\ EULAR December 2020 viewpoints on SARS-CoV-2 vaccination in patients with RMDs
}

\author{
Johannes WJ Bijlsma
}

Handling editor David S Pisetsky

Rheumatology, UMCUtrecht, Utrecht, The Netherlands

\section{Correspondence to}

Dr Johannes WJ Bijlsma, Rheumatology \& Clinical Immunology, UMCUtrecht, Utrecht 3584CX, The Netherlands;

j.w.j.bijlsma@gmail.com

Received 6 January 2021 Revised 22 January 2021

Accepted 1 February 2021 Published Online First 9 February 2021

Check for updates

(C) Author(s) (or their employer(s)) 2021. Re-use permitted under CC BY-NC. No commercial re-use. See rights and permissions. Published by BMJ.

To cite: Bijlsma JWJ.

Ann Rheum Dis

2021:80:411-412
The COVID-19 pandemic has severely influenced all aspects of life in 2020. This pandemic also affected patients with rheumatic and musculoskeletal diseases (RMDs) and impacted the care given to them. With the development of vaccines, the future is becoming brighter. The possibility of vaccination however also raises a lot of questions, especially for patients with inflammatory RMDs and patients who are treated with drugs that may influence their immune system. To address these questions EULAR has formed a Task Force of representatives of its constituents, patients, health professionals and rheumatologists experienced in the field which addressed pertinent aspects.

This information is based on knowledge available at this moment in time, realising that specific data about the performance of the emerging vaccines to COVID-19 in patients with RMDs and in patients treated with drugs that influence the immune system are not yet available. In the coming months we expect that more relevant information will be collected. When you read this information, please realise that this text will need to be updated when new information becomes available.

In general, several different kinds of vaccines will be used in national vaccination programmes. Vaccines that are presently being used or under development specifically for COVID-19 are nonlive vaccines, that cannot give you the viral disease, that cannot transfer infection to you, nor can they change your genetic information. These vaccines can be used safely in patients with RMDs as well as in patients receiving drugs that influence the immune system. Other non-live vaccines have been proven to work for immune-suppressed patients. To say it more strongly, there is no reason to withhold these vaccines from patients with RMDs and patients treated with drugs that influence the immune system.

The following different SARS-CoV-2 vaccines are presently in a more advanced stage of development and some have been approved in different countries. Vaccines based on mRNA (such as those from Pfizer/BioNTech and from Moderna), on proteins with adjuvant (such as from Novavax) and on nonreplicable vectors (such as from AstraZeneca and from Janssen).

Vaccinations should preferably be given when the disease is in a quiet phase; it is also preferred to vaccinate before planned immunosuppression if feasible. But of course, this is not always possible. A vaccination is most effective when the amount of, or level of immune suppression is low; however, the risk of a flare of the disease is real, and therefore it is not advised to decrease your medication.
Of course, in specific cases your physician can make other choices, based on your personal condition and/or on the drugs you are using; if you are in doubt consult your rheumatologist.

Independent from vaccination for SARS-CoV-2, vaccination against pneumococcus and influenza is highly recommended in patients with RMDs and patients treated with drugs that influence the immune system.

\section{FREQUENTLY ASKED QUESTIONS BY PATIENTS WITH RMDS AND PATIENTS USING DRUGS THAT INFLUENCE THE IMMUNE SYSTEM}

Do I need to be vaccinated? It is wise for everybody to be vaccinated against COVID-19.

Do I need to get an urgent vaccination? Countries have completely different rules. Many countries place, at this moment, age and residents and staff in care homes at the top of their priorities list.

Is one vaccine better for me than another one? Too early to say and there are not studies comparing vaccines; with the present info vaccination by any vaccine is better than no vaccination at all.

I had COVID-19 and recovered from it. Should I be vaccinated? At present, there are no data; but vaccination after COVID-19 is considered to be safe and potentially confers additional protection.

Can I get the vaccination if I take my antirheumatic or immunosuppressive drugs? Yes, you can. The only exception could be rituximab; in case you use rituximab it will depend on when you last received the drug, please consult your rheumatologist.

Do vaccines interfere with my medication? No.

Who should I consult before vaccination-my GP or my rheumatologist? If you have specific questions your rheumatologist would be the preferred source of information.

What data are necessary to take the right decision? Knowledge of your disease activity, drug treatment and possible comorbidities.

What about side effects? It is rather early for a definite answer, but so far, the vaccines that are tested are remarkably safe, comparable with those we know from the influenza vaccination.

What should I do in case of a flare? Contact your rheumatologist to discuss.

In case I have worrying side effects? This is unlikely, but contact your rheumatologist.

Does the vaccine activate my illness? This is unlikely, but we don't have enough experience yet.

Will I need a vaccination annually as with other vaccinations for example, influenza? Not known yet, but quite likely. 
What about long-term effects? It is rather early for a definite answer, but so far, the vaccines that are tested are remarkably safe.

Am I more at risk of getting COVID-19 disease? No there is no evidence that the risk of getting the disease is higher in patients with RMDs.

Am I more at risk of getting worse COVID-19 disease? Not by your disease itself; but-like in everybody-when there is major organ damage (such as renal dialysis for kidney failure, severe lung involvement) the risk can be higher.

Do my treatments increase the risk of worse disease? Most of the drugs used in RMD have not been associated with worse disease. To date the only treatments that have been shown to be associated with a worse COVID-19 outcome are using more than $10 \mathrm{mg}$ glucocorticoids daily or being treated with rituximab.
Contributors This is a product of the EULAR COVID-19 Task Force. JWJB is just the reporter on behalf of this Task Force.

Funding The authors have not declared a specific grant for this research from any funding agency in the public, commercial or not-for-profit sectors.

Competing interests None declared.

Patient and public involvement Patients and/or the public were involved in the design, or conduct, or reporting or dissemination plans of this research.

Patient consent for publication Not required.

Provenance and peer review Not commissioned; externally peer reviewed.

Open access This is an open access article distributed in accordance with the Creative Commons Attribution Non Commercial (CC BY-NC 4.0) license, which permits others to distribute, remix, adapt, build upon this work non-commercially, and license their derivative works on different terms, provided the original work is properly cited, appropriate credit is given, any changes made indicated, and the use is non-commercial. See: http://creativecommons.org/licenses/by-nc/4.0/.

ORCID ID

Johannes WJ Bijlsma http://orcid.org/0000-0002-0128-8451 